Çukurova Üniversitesi Mühendislik Mimarlık Fakültesi Dergisi, 33(3), ss. 121-132, Eylül 2018

Çukurova University Journal of the Faculty of Engineering and Architecture, 33(3), pp. 121-132, September 2018

\title{
Elektronik Sistemlerin Soğutulmasında Nanoakışkanlar ve Çarpan Jetlerin Müşterek Etkisinin İncelenmesi
}

\author{
Mustafa KILIÇ*1 \\ ${ }^{1}$ Adana Bilim ve Teknoloji Üniversitesi, Mühendislik Fakültesi, Makine Mühendisliği Bölümü, \\ Adana
}

Geliș tarihi: 12.06.2018～Kabul tarihi: 15.10 .2018

\section{$\ddot{O} z$}

Bu çalışmada; gelişen teknolojilere bağlı olarak artan elektronik elemanların 1sıl yük problemini çözmek maksadıyla, yüksek 1sı akılı bir yüzeyden olan 1sı transferinin, nanoakışkanların çarpan akışkan jet tekniği ile kullanılarak iyileştirilmesi sayısal olarak incelenmiştir. Farklı hacim oranları, farklı 1sı akıları ve farklı tipte hazırlanan nanoakışkanların ısı transferine etkisi çalışmada kullanılan parametrelerdir. Çalışmada

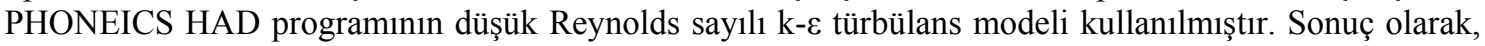
hacimsel oran $\% 2$ 'den $\% 8$ 'e artırıldığında ortalama Nusselt sayısında \%15,2 oranında bir iyileşme tespit edilmiştir. Yüzeydeki 1Sı akısı iki kat artırıldığında, yüzey sıcaklıklarının arttığı ancak yerel Nusselt sayısında belirgin bir değişiklik olmadığı tespit edilmiştir. $\mathrm{Cu}-\mathrm{H}_{2} \mathrm{O}$ nanoakışkanı kullanılması durumunda, ortalama Nusselt sayisinda sirasiyla $\mathrm{CuO}-\mathrm{H}_{2} \mathrm{O}, \mathrm{TiO}_{2}-\mathrm{H}_{2} \mathrm{O}, \mathrm{Al}_{2} \mathrm{O}_{3}-\mathrm{H}_{2} \mathrm{O}$ ve saf suya göre $\% 2,6, \% 5,5$, $\% 6,1, \% 9,6$ iyileşme olduğu gözlemlenmiştir. Sayısal modelde kullanılan düşük Reynolds sayılı k- $\varepsilon$ türbülans modelinin sıcaklık dağılımını ve akış özelliklerini iyi bir şekilde temsil edebildiği görülmüştür.

Anahtar Kelimeler: Çarpan jet, Elektronik sistemler, Isı transferi, Nanoakışkanlar

\section{Investigation of Combined Effect of Nanofluids and Impinging Jets on Cooling of Electronic Systems}

\begin{abstract}
At this study, to solve the problem of high heat loads of electronic systems, enhancement of heat transfer from a high heat flux surface with nanofluids and impinging jet technique was investigated numerically. Effect of different volume ratios, different heat fluxes and different nanofluids and pure water on heat transfer are the parameters of this study. Low Reynolds k- $\varepsilon$ turbulence model of PHONEICS CFD code was used at this study. As a result, it was obtained that increasing volume ratio from $2 \%$ to $8 \%$ causes an increase of $15.2 \%$ on average Nusselt number. Increasing heat flux on the surface two times causes an increase on surface temperature but does not cause any significant increase on local Nusselt number. Using $\mathrm{Cu}-\mathrm{H}_{2} \mathrm{O}$ nanofluid causes an increase of $\% 2.6, \% 5.5, \% 6.1$ and $\% 9.6$ on average Nusselt number with respect to $\mathrm{CuO}-\mathrm{H}_{2} \mathrm{O}, \mathrm{TiO}_{2}-\mathrm{H}_{2} \mathrm{O}, \mathrm{Al}_{2} \mathrm{O}_{3}-\mathrm{H}_{2} \mathrm{O}$ and pure water. It was seen that the low Reynolds number k- $\varepsilon$ turbulence model well represent the temperature distribution and flow properties in this study.
\end{abstract}

Keywords: Impinging jet, Electronic systems, Heat transfer, Nanofluids

*Corresponding author (Sorumlu yazar): Mustafa KILIÇ, mkiliç@adanabtu.edu.tr 


\section{GİRIŞ}

Günümüzde hızla gelişen teknolojiler elektronik sistemlerin 1sıl yüklerini her geçen gün artırmakta ve soğutma ihtiyacı daha kritik hale gelmektedir. Elektronik sistemlerin isıl yükü probleminin çözülmesi önemli bir teknolojik kırılmayı da beraberinde getirecektir. Gelecek yüzyılın teknolojisi olarak değerlendirilen nanoteknoloji ise bu teknolojik kırılmayı sağlayacak önemli bir adım olarak değerlendirilebilir. Nanoteknoloji alanında yapılan önemli çalışmalardan birisi de nanoakışkanların kullanılmasıdır.

Geleneksel ısı transferi akışkanlarının içerisine nano boyutta parçacıkların, belirli hacimsel oranlarda katılarak oluşturulan süspansiyonlara "nanoakışkan" denir. Nanoakışkan kullanılarak yapılan 1sı transferi uygulamalarında; akışkan içerisine süspanse edilen parçacıklar akışkanın ısıl kapasitesini arttırırlar. Parçacıklar arasındaki etkileşim ve çarpışmalar akış içerisinde çalkantılara ve türbülans şiddetinin artmasına neden olur. Böylece, daha yüksek 1s1 iletimi ile birlikte çalkantı şiddeti ve geniş yüzey alanı daha çok 1sı transferine izin verir. Nano parçacıklar atomların \%20'sini yüzeyinde taşırlar bu durum onları 1sı iletimi için hazır hale getirir. Nanoakışkanların diğer bir avantajı ise; çok küçük boyutlarından dolayı sıvıda mikro taşınımı ortaya çıkaran ve bundan dolayı 1sı transferini artıran parçacık hareketliliğidir. Bu üstün özelliklerinden dolayı nanoakışkanlar özellikle yüksek 1Sı akılı yüzeylerden olan isı transferi uygulamalarında olmak üzere, endüstri, tıp, uzay araştırmaları gibi birçok alanda uygulama alanı bulabilmektedir.

Çarpan jetler, dar bir bölgede yüksek 1sı transferi elde etmemizi sağlayan önemli bir 1sı transferi arttırma tekniğidir. $\mathrm{Bu}$ amaçla çeşitli çaplarda nozul veya lüleler kullanılmaktadır. Yüzeye çarpan akışkan yüzeyde yüksek 1sı transfer katsayıs1 oluşturur. Birçok mühendislik uygulamalarında kullanılan jet çarpma tekniği uygulamada gaz türbinlerinin kanatçıklarının soğutulmasında, cam temperleme, metallerin ısıl işlemlerinde, kâğıt ve tekstil ürünlerinin kurutulmasında, otomotiv uygulamalarında [1] boya, gida sanayi, mikroişlemcilerin soğutulmasında, ısıtma ve pişirme amaçlı işlemlerde kullanılmaktadır. Literatürdeki nanoakışkanlar ve çarpan jetlere ilişkin çalışmalar incelendiğinde aşağıda özetlenen sonuçların elde edildiği görülebilir.

Temel akışkan olarak $\mathrm{Al}_{2} \mathrm{O}_{3}$-su nanoakışkanı kullanılan çalışmalar kapsamında, Teamah ve arkadaşları [2] $\mathrm{Al}_{2} \mathrm{O}_{3}$-su nanoakışkanının düz bir plakaya çarptırılması ile oluşan 1sı transferini ve akış yapısını sayısal ve deneysel olarak farklı Reynolds sayılarında $(\mathrm{Re}=3000-32000)$ ve nanoakışkan hacim oranlarında ( $\phi=\% 0-10)$ incelemiştir. Akışkan içindeki nanopartükülleri artırdıkça, akışkan olarak yalnız suyun kullanıldığı duruma göre yüzeyden olan 1sı transferinin arttığı, 1Sı transfer katsayısında \% 62 oranında bir artış sağlanabildiği, akışkan olarak $\mathrm{CuO}$ kullanıldığında ise, 1S1 transferinde $\mathrm{Al}_{2} \mathrm{O}_{3}$ nanoakışkanı kullanılma durumuna göre $\% 8,9$ ve $\mathrm{TiO}_{2}$ nanoakışkanı kullanılma durumuna göre \%12 oranında bir artış sağlanabildiği görülmüştür. Manca ve arkadaşları [3] saf su ve $\mathrm{Al}_{2} \mathrm{O}_{3}$-su nanoakışkanı kullanıldığı durumda, sınırlandırılmış çarpan jetlerin sabit 1sı akılı düz bir plakadan olan 1sı transferine etkisini incelemiştir. Jet Reynolds sayısı $(\mathrm{Re}=100-400)$ ve boyutsuz kanal yüksekliği $(\mathrm{H} / \mathrm{W}=4-10)$ çalışmada kullanılan parametrelerdir. Reynolds sayısı ve akışkan içerisindeki partükül konsantrasyonu arttıkça yerel 1sı transfer katsayısının ve Nusselt sayısını arttığı, ortalama 1Sı transfer katsayısındaki en yüksek artışın (\%36) $\mathrm{H} / \mathrm{W}=10$ ve nanoakışkan hacim oranlarını $\phi=\% 5$ olduğu durumda elde edildiği ifade edilmiştir. $\mathrm{Qu}$ ve arkadaşları [4] nanaoakışkan olarak $\mathrm{Al}_{2} \mathrm{O}_{3}$-su kullandıkları deneysel çalışmalarında kapalı devre titreşimli 1sı borusunun 1sıl performansını incelemişlerdir. Sonuç olarak sistem 1sıl direncinin saf su kullanımına göre \%32,5 azaldığını tespit etmişlerdir. Lv ve arkadaşları [5] $\mathrm{Al}_{2} \mathrm{O}_{3}$-su nanoakışkanının farklı hacimsel oranlarda $(\% 0,5$, $\% 1, \quad \% 1,5, \quad \% 2)$ farklı çarpma açılarında $\left(\Theta=50^{\circ}, 70^{\circ}, 90^{\circ}\right)$, ve farklı Reynolds sayılarında $(\mathrm{Re}=5000-14000)$ 1s 1 transferine etkisini deneysel olarak incelemiştir. $\mathrm{Al}_{2} \mathrm{O}_{3}$-su nanoakışkanının $\mathrm{H} / \mathrm{D}_{\mathrm{h}}=4, \quad \% 2$ hacimsel oranda, $\mathrm{Re}=12000$ değerinde saf suya göre 1s1 transferinde \%61,4 iyileşme sağlayabildiğini tespit etmişlerdir. 
Khaleduzzaman ve arkadaşları [6] yaptıkları deneysel çalışmada, elektronik devre elemanlarının soğutulması sürecinde farklı hacimsel oranlarda $(\% 0,1-\% 0,25) \quad$ hazırladikları $\quad \mathrm{Al}_{2} \mathrm{O}_{3}-\mathrm{Su}$ nanoakışkanın enerji ve ekserji analizini yapmıştır. Sonuç olarak, nanoparçacık hacimsel oranı arttıkça, nanoakışkan ısı iletim katsayısının, vizkositesinin, yoğunluğunun, enerji veriminin ve ekserjisinin arttığ1, özgül ısısının ise azaldığ edilmiştir.

Temel akışkan olarak $\mathrm{Cu}$-su nanoakışkanı kullanılan çalışmalar kapsamında; Shang ve arkadaşları [7] Cu-su nanoakışkanı ile kapalı devre titreşimli bir 1Sı borusunun 1sı transferi özelliklerini incelemiştir. Saf su ile karşılaştırıldığında bu nanoakışkanın kullanıldığı durumda sistemin 1S1 aktarma kapasitesinin \%83 oranında artırılabildiği görülmüştür. Wang ve arkadaşları [8] Cu-su nanoakışkanı için farklı Re sayılarında $(\mathrm{Re}=$ 2000-12000) tek fazlı ve çok fazlı nanoakışkan davranışını sayısal olarak incelemiştir. Temel akışkana nanoparçacık eklenmesinin, 1sı iletim katsayısını arttırmasının ötesinde akışkan karakteristiğini önemli ölçüde etkilediği, bu sebeple tek fazlı akış için kullanılan türbülans modellerinin (k- $\varepsilon, \mathrm{k}-\omega, \mathrm{RNG}$ vb.) akış1 yeteri kadar modelleyemeyeceği, bunun yerine SST k-w türbülans modeli, Eulerian-Eulerian türbülans modeli gibi çok fazlı modellerin tercih edilmesi gerektiği ifade edilmiştir.

Temel akışkan olarak CuO-su nanoakışkanı kullanılan çalışmalar kapsamında; Sun ve arkadaşları [9] $\mathrm{CuO}$ nanoakışkanı kullanılan tek bir çarpan jetin 1sı transferine etkisini incelemiştir. Nanoakışkan kullanıldığında yalnızca su kullanılması durumuna göre 1sı transferinde önemli bir artış sağlanabildiği, basınç düşüşünde önemli bir değişim olmadığı, dairesel nozul kullanıldığında, kare şekilli nozula göre daha yüksek 1sı transfer katsayısı elde edildiği, jet açısı $90^{\circ}$ olduğunda en yüksek 1s1 transferinin elde edildiği belirlenmiştir. Umer ve arkadaşları [10] $\mathrm{CuO}-\mathrm{Su}$ nanoakışkanı kullanarak laminer akış şartlarında sabit 1S1 akılı bir yüzeyden olan 1S1 transferini faklı hacimsel oranlarda incelemişlerdir.
Sonuç olarak parçacık hacim oranı arttıkça ve Reynolds sayısı arttıkça ısı transfer katsayısının da arttığı, 1Sı transfer katsayısındaki en yüksek artışın (\%61) parçacık hacim oran $1 \% 4$ ve Reynolds sayısı $\mathrm{Re}=605$ olduğu durumda gerçekleştiğini tespit etmişlerdir.

Kang ve arkadaşları [11] gümüş nanoparçacıklar ve saf su kullanarak teşkil ettikleri nanoakışkan ile yaptıkları deneysel çalışmada; saf su kullanımına göre $10 \mathrm{~nm}$ nanoparçacıklar kullanıldığında isıl dirençte $\% 50$ ve $35 \mathrm{~nm}$ çaplı nanoparçacıklar kullandıklarında \%80 oranında azalma olduğunu belirlemişlerdir.

Temel akışkan olarak $\mathrm{SiO}_{2}$-su nanoakışkanı kullanılan çalışmalar kapsamında, Lv ve arkadaşları [12] $\mathrm{SiO}_{2}$-su nanoakışkanının farklı hacimsel oranda $(\% 1, \% 2, \% 3)$, farklı $\mathrm{Re}$ sayılarında $(\mathrm{Re}=8000-13000)$, farkl1 jet-plaka mesafelerinde $\left(\mathrm{H} / \mathrm{D}_{\mathrm{h}}=2,3,4,5\right)$ 1si transferine olan etkisini deneysel olarak incelemiştir. Sonuç olarak; $\mathrm{SiO}_{2}$-su nanoakışkanının \%3 hacimsel oranda, $\mathrm{Re}=13000$ değerinde saf suya göre 1S1 transfer katsayısının \%40 artırılabileceğini tespit etmişlerdir.

Temel akışkan olarak $\mathrm{TiO}_{2}$-su nanoakışkanı kullanılan çalışmalar kapsamında, Sing ve arkadaşları [13] $\mathrm{TiO}_{2}$-su nanoakışkanının laminer akış şartlarında kaynama ile 1sı transferine etkisini farklı hacimsel oranlarda $(\% 0,1, \% 0,5, \% 1)$ incelemişlerdir. Sonuç olarak, hacimsel oran ve Re sayısı artıkça kaynama kritik ısı akısının da (hacimsel oran \%0,5 artışında kaynama kritik 1s1 akısı \%40 artmaktadır) artı̆̆̆ını tespit etmişlerdir.

Farklı tipte nanoakışkanların ısıl performanslarının karşılaştırıldığı çalışmalar kapsamında, Kılıç ve Özcan [14] yüksek 1S1 ak1lı bir yüzeyden olan 1s1 transferini farklı nanoakışkanlar ve çoklu jetler için incelemişlerdir. Re sayısındaki artışın ve parçacık çapındaki azalmanın ısı transferinde artışa sebep olduğunu, $\mathrm{Cu}$-su nanoakışkanı kullanma durumunda, $\mathrm{Al}_{2} \mathrm{O}_{3}$-su nanoakışkanına göre \%9,3 ve TiO-su nanoakışkanına göre $\% 8,4$ artış sağlanabildiğini tespit etmişlerdir. Nayak ve 
arkadaşları [15] $\mathrm{Al}_{2} \mathrm{O}_{3}$ ve $\mathrm{TiO}_{2}$ nanoakışkanlarının ısıl performanslarını karşılaştırmış ve farklı hacimsel oranlarda $(\% 0,01, \% 0,03, \% 0,05, \% 0,07)$ iki adet çarpan nanoakışkan jetin ısı transferine etkisini deneysel olarak incelemiştir. Sonuç olarak, bu iki farklı nanoakışkanın benzer performans gösterdiğini, 1sı transferindeki artışın 1s1 iletim katsayısının artışından çok, nanaoparçacıkların akış içerisindeki davranışından kaynaklandığını, bu sebeple $\mathrm{Al}_{2} \mathrm{O}_{3}$-su nanoakışkanının daha homojen bir dağılım sağlayabildiğinden $\mathrm{TiO}_{2}$-su nanoakışkanından daha iyi bir performans gösterdiğini tespit etmişlerdir.

Çarpan akışkan jetlerin deneysel uygulamaları kapsamında, Yan ve arkadaşları [16] kanal akışı ile jet akışının birlikte uygulandığ durumda 1sı transferini incelemişlerdir. Kanal akışında $(\mathrm{Re}=10000-40000)$ aralığında, jet akışında $(\operatorname{Re}=5000-20000)$ aralığındadır. Sonuç olarak, hat şeklindeki aksial kanatçıkların uygulanması durumunda kanatçıkların olmama durumuna göre \%50-\%90’lık bir artış olduğunu, çarpmalı jetin uygulanmasının kanal akışına göre ısı transferini artırdığını belirlemişlerdir. Genel olarak geçirgen köpük kullanılmasının 1sı transferini artırdığ 1 , bu durumun Re sayısı arttıkça daha da arttığı, geçirgen köpük kullanıldığında kanatçıkların kullanılma durumuna göre daha fazla basınç kaybı olduğu ancak 1S1 transferini artırdığı tespit edilmiştir.

Kılıç ve arkadaşları [17] sabit 1sı akılı düz bir plakanın çarpan akışkan hava jeti yardımı ile soğutulmasını farklı Reynolds sayıları ve boyutsuz kanal yükseklikleri için incelemiştir. Ortalama Nusselt sayısının $\mathrm{Re}=4000-10000$ aralığında $\% 49,5, \mathrm{H} / \mathrm{D}_{\mathrm{h}}=4-10$ aralığında ise, $\% 17,9$ oranında arttığ1 tespit edilmiştir.

McGuinn ve arkadaşları [18] iki ayrı çıkış geometrisine sahip (düz çıkışlı ve şekil verdirilmiş) nozuldan oluşturulan akışın sağladığ 1sı transferini incelemişlerdir. Çalışma sayısal ve deneysel bir çalışmadır. Çalışma sonucunda, şekil verdirilmiş nozulun düz nozula göre daha etkin bir 1S1 transferi sağladığı gözlenmiştir. Yüzeydeki 1S1 transferinin yalnızca oluşan türbülanslara bağlı olmadığı aynı zamanda yüzeye gelen akış geometrisine de bağlı olduğu tespit edilmiştir.

Çarpan akışkan jetlerin sayısal uygulamaları kapsamında, Isman ve arkadaşları [19] sabit yüzey 1S1 akısına sahip sınırlandırılmamış bir plakanın bir tek çarpmalı jet ile soğutulmasını incelemişlerdir. Çalışma sayısal bir çalışmadır. Akışkanın türbülanslı, iki boyutlu ve sürekli halde olduğu kabulü yapılmıştır. RNG ve standart k- $\varepsilon$ modelinin diğer modellere göre daha çok yakınsadığı ifade edilmiştir. Re sayısı 4000-12000 ve nozul plaka mesafesinin-nozul çapına oranı 4-10 aralığında alınmıştır. Sonuç olarak, Re sayısı artırılarak ya da nozul-plaka mesafesi azaltılarak is1 transferinin artırılabileceği tespit edilmiştir.

$\mathrm{Bu}$ çalışmanın literatürde yer alan çalışmalardan temel farklılıkları ise şu şekilde özetlenebilir: $\mathrm{Bu}$ gün için, nanoakışkanlar alanında yapılan akademik çalışmalar son derece kısıtlıdır. Nanoakışkanlarla ilgili çalışmaların büyük bir çoğunluğu fiziksel ve termal özelliklerinin karakterizasyonu ile ilgilidir. Hatta nanoakışkanların farklı soğutma teknikleri ile kullanılmasına yönelik çalışmalar yok denecek kadar azdır. $\mathrm{Bu}$ nedenle bu çalışma nanoakışkanların yüksek 1sı akılı yüzeylere sahip elektronik sistemlerin soğutulmasında öncü çalışmalardan birisi olacaktır.

Literatürde nanoakışkanlar (sınırlı sayıda) ve çarpan jetlere yönelik ayrı ayrı çalışmalar mevcut olmasına rağmen; nanoakışkanların çarpan jet tekniği ile kullanılmasına yönelik çalışma son derece sınırlıdır. $\mathrm{Bu}$ çalışmadaki temel motivasyon; son derece karmaşı olan çarpan jet hidrodinamik davranışının ve bunun ısı transferine etkisinin anlaşılmasının yanı sıra nanoparçacıkların bu karmaşık fiziksel sürece etkisinin belirlenmesinin sağlanmasıdır. $\mathrm{Bu}$ çalışmada; farklı hacim oranlarının $(\% 2, \% 4, \% 6, \% 8)$, farklı 1S1 ak1larının ( $q=150,200,250,300 \mathrm{~W})$ ve farklı tipte nanoakışkanların $\left(\mathrm{Cu}-\mathrm{H}_{2} \mathrm{O}, \mathrm{CuO}-\mathrm{H}_{2} \mathrm{O}\right.$, $\left.\mathrm{TiO}_{2}-\mathrm{H}_{2} \mathrm{O}, \quad \mathrm{Al}_{2} \mathrm{O}_{3}-\mathrm{H}_{2} \mathrm{O}\right) \quad$ is 1 transferine etkisi incelenmiştir. 


\section{SAYISAL MODEL VE MATEMATIKSEL FORMÜLASYON}

$\mathrm{Bu}$ çalışmada, elektronik sistemlerin önemli problemlerinden olan yüksek 1sı akılı bir yüzeyden olan 1s1 transferinin, nanoakışkanların çarpan akışkan jet tekniği ile kullanılarak iyileştirilmesi sayısal olarak incelenmiştir. Hedef plaka boyutları 90x15x2 mm (boy x genişlik x yükseklik) olarak modellenmiştir. x-y düzlemi üzerine yerleştirilmiş, elektronik devre elemanını modelleyen bakır plakanın yüzeyindeki sabit ısı akısı $222000 \mathrm{~W} / \mathrm{m}^{2}$ $(q=300 \quad W)^{\prime}$ dır. Nozul hidrolik çap1 $\mathrm{D}_{\mathrm{h}}=3,5 \mathrm{~mm}$ 'dir.

$\mathrm{Bu}$ sayısal analiz için PHONEICS HAD programının düşük Re sayılı k- $\varepsilon$ türbülans modeli kullanılmıştır. Bu model; sınırlandırılmış çarpan jet uygulamalarında, duvar etkilerini de dâhil etmesi ve uygulanan Reynolds değerinde, deney sonuçları ile uyumlu sonuçlar elde edilebilmesi [20] sebebiyle tercih edilmiştir.

Sayısal olarak incelenen modelin geometrisi Şekil 1'de ve hücre yapısı Şekil 2'de gösterilmiştir.

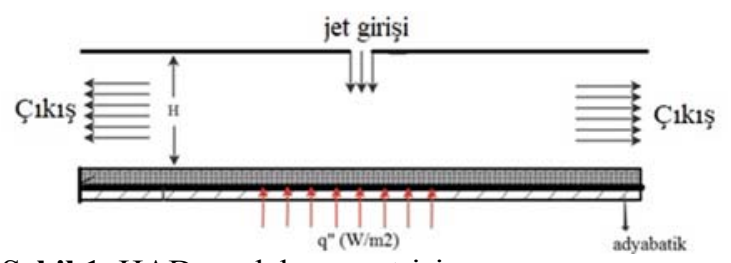

Şekil 1. HAD model geometrisi

Kütlenin korunumu, momentum ve enerji denklemlerine uygun sınır şartları verilerek oluşturulan model sürekli şartlarda olup, çevreye radyasyon ile olan isı transferi ihmal edilmiş, sadece türbülanslı, zorlanmış taşınımla olan 1sı transferi dikkate alınmıştır. Ayrıca jet giriş sıcaklığ $\mathrm{Tj}=20^{\circ} \mathrm{C}$ olarak modellenmiştir. Modelde kullanılan sınır şartları Çizelge 1'de sunulmuştur.

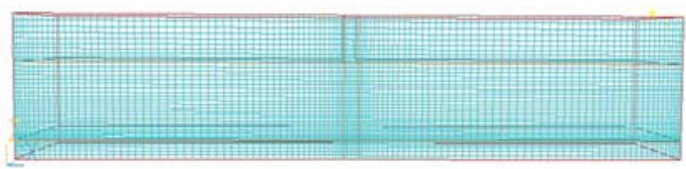

Şekil 2. Hücre yapısı
Çizelge 1. Sınır şartları

\begin{tabular}{|c|c|c|c|c|c|c|}
\hline & $U(\mathrm{~m} / \mathrm{s})$ & $V(m / s)$ & $W(\mathrm{~m} / \mathrm{s})$ & $T(E)$ & $k$ & $s$ \\
\hline Jet & $U=0$ & $V=0$ & $\mathbb{W}=\mathbb{K}_{0}$ & $T=I_{\text {ow }}$ & $\left(\tau_{1} W_{j e t}\right)^{2}$ & $\left(c_{\mu} c_{s}\right)^{3 / 4} \frac{k^{3 / 2}}{l}$ \\
\hline Plaka & $U=0$ & $V=0$ & $\mathrm{~W}=0$ & $a^{*}=e^{*}=$ & $k=0$ & $\frac{\partial t}{\partial z}=0$ \\
\hline Cilas & $\frac{\partial v}{\partial x}=0$ & $\frac{\partial v}{\partial x}=0$ & $\frac{\partial w}{\partial x}=0$ & $\mathrm{~T}=\mathrm{I}_{\text {cous }}$ & $\frac{\partial k}{\partial x}=0$ & $\frac{\partial t}{\partial x}=0$ \\
\hline $\begin{array}{l}\text { On } \\
\text { Duvar }\end{array}$ & $U=0$ & $V=0$ & $W=0$ & $\frac{\partial \tau}{\partial y}=0$ & . & . \\
\hline $\begin{array}{l}\text { Ûst } \\
\text { Duvar }\end{array}$ & $\mathrm{U}=0$ & $V=0$ & $\mathrm{~W}=0$ & $\frac{\partial v}{\partial z}=0$ & - & - \\
\hline
\end{tabular}

Süreklilik, türbülanslı momentum ve enerji denklemleri aşağıda sunulmuştur.

Süreklilik denklemi:

$$
\frac{\partial U_{i}}{\partial x_{i}}=0
$$

Momentum denklemi:

$\rho U_{i} \frac{\partial U_{j}}{\partial x_{i}}=-\frac{\partial P}{\partial x_{j}}+\frac{\partial}{\partial x_{i}}\left[\mu\left(\frac{\partial U_{i}}{\partial x_{j}}+\frac{\partial U_{j}}{\partial x_{i}}\right)-\rho \overline{u_{i}^{\prime} u_{j}^{\prime}}\right]$

Enerji denklemi:

$\rho c_{p} U, \frac{\partial T}{\partial x_{i}}=\frac{\partial}{\partial x_{i}}\left[k \frac{\partial T}{\partial x_{i}}-\rho c_{p} \overline{u_{i}^{\prime} T^{\prime}}\right]$

Yüzeyden olan 1sı transferi iletim, taşınım ve ışınım ile gerçekleşecektir.

$\mathrm{Q}_{\text {taşıım }}=\mathrm{Q}_{\text {toplam }}-\mathrm{Q}_{\text {iletim }}-\mathrm{Q}_{\text {1̧̧ııım }}$

Plaka boyunca meydana gelecek iletimle 1s1 transferi;

$Q_{\text {iletim }}=\frac{-k_{c} \cdot A \cdot\left(T_{\text {alt }}-T_{\text {isst }}\right)}{L_{c}}$

Burada; $\mathrm{k}_{\mathrm{c}}$ bakır plakanın 1sı iletim katsayıs1, A bakır plaka yüzey alanı, $\mathrm{L}_{c}$ ise bakır plaka kalınlığıdır.

Yüzeyden konveksiyonla olan 1sı transferi; 


$$
\mathrm{Q}_{\mathrm{taagmm}}=\mathrm{h} \cdot \mathrm{A} \cdot \Delta \mathrm{T}
$$

Burada h 1sı taşınım katsayısı, A taşınım yüzey alanı, $\Delta \mathrm{T}\left(\Delta \mathrm{T}=\mathrm{T}_{\mathrm{w}}-\mathrm{T}_{\mathrm{ygn}}\right)$ ölçülen yüzey sıcaklığı ile akışkan ortalama yığın sıcaklığı arasındaki farktır.

Nusselt sayısı $(\mathrm{Nu})$; taşınımla olan 1 sı transferinin iletimle olan 1s1 transferine oranını gösteren boyutsuz parametredir. Nusselt sayısı;

$$
\mathrm{Nu}=\frac{\left(\mathrm{Q}_{\text {tas̆mm }} \cdot \mathrm{D}_{\mathrm{h}}\right)}{\left(\mathrm{T}_{\text {yüzey }}-\mathrm{T}_{\text {y̆̆ğ }}\right) \cdot \mathrm{k}_{\mathrm{nf}}}
$$

Burada $T_{\text {yüzey }}$ ölçülen yüzey sıcaklığ $1, D_{h}$ hidrolik çap ve $\mathrm{k}_{\mathrm{nf}}$ ise nanoakışkan 1sıl iletkenlik katsayısıdir.

Reynolds sayısı (Re); zorlanmış taşınımda akışın laminer veya türbülanslı olup olmadığını belirlemek için kullanılmaktadır. Türbülanslı akışa esas Reynolds sayısı;

$$
\operatorname{Re}=\frac{\left(\rho_{n f} \cdot V_{j e t} \cdot D_{h}\right)}{\left(\mu_{n f}\right)}
$$

Burada $\rho_{\text {nf }}$ nanoakışkan yoğunluğu, $V_{\text {jet }}$ jet çıkış hızı ve $\mu_{\mathrm{nf}}$ nanoakışkan dinamik vizkozitesidir. Nanoakışkan yoğunluğu ise;

$$
\rho_{n f}=(1-\varphi) \cdot \rho_{b f}+\varphi \cdot \rho_{p}
$$

Burada $\rho_{\mathrm{bf}}$ temel akışkan (su) yoğunluğu, গ nanoakışkan hacimsel oranı, $\rho_{p}$ ise nanoakışkan içerisindeki katı parçacıkların yoğunluğudur. Nanoakışkan hacimsel oranı ise;

$$
\vartheta=\frac{1}{(1 / \omega) \cdot\left(\rho_{p}-\rho_{b f}\right)}
$$

Burada $\omega$ nanoakışkan ile temel akışkanın (su) yoğunlukları arasındaki farktır. Nanoakışkan özgül 1sis1 ise;

$$
C_{p_{n f}}=\frac{\vartheta \cdot\left(\rho \cdot C_{p}\right)_{p}+(1-\vartheta) \cdot\left(\rho \cdot C_{p}\right)_{f}}{\left(\rho_{n f}\right)}
$$

Burada $C p_{(p)}$ parçacı̆̆ın özgül ${ }_{1 S 1 S 1}, C p_{(f)}$ temel akışkanın özgül ısısıdır. Nanoakışkanın ısıl iletim katsayısı ise [21];

$\frac{\mathrm{k}_{\text {eff }}}{\mathrm{k}_{\mathrm{f}}}=1+4,4 \operatorname{Re}_{(\mathrm{p})}^{0,4} \operatorname{Pr}^{0,66}\left(\frac{\mathrm{T}}{\mathrm{T}_{\mathrm{fr}}}\right)^{10}\left(\frac{\mathrm{k}_{\mathrm{p}}}{\mathrm{k}_{\mathrm{f}}}\right)^{0,03} \phi^{0,66}$

Burada $\operatorname{Re}_{(\mathrm{p})}$ nanoparçacık Reynolds sayısı, $\operatorname{Pr}$ temel akışkanın Prandtl sayısı. $\mathrm{k}_{\mathrm{p}}$ nanoparçacıkların ısıl iletim katsayısı, $\varphi$ parçacık hacimsel oranı, T nanoakışkanın sıcaklığ $1(\mathrm{~K}), \mathrm{T}_{\mathrm{fr}}$ temel akışkanın donma noktasıdır. Nanoparçacık Reynolds sayısı ise;

$R e=\frac{2 \rho_{f} k_{b} T}{\pi \mu_{f}^{2} d_{p}}$

$K_{\mathrm{b}}$ Boltzmann's sabitidir. Nanoakışkanın dinamik vizkozitesi ise şu şekilde hesaplanmıştır.

$\mu_{\mathrm{nf}}=\mu_{\mathrm{bf}}\left(1+2,5 \varphi+4,698 \varphi^{2}\right)$

\subsection{Sayısal Sonuçların Doğrulanması}

$\mathrm{Bu}$ çalışmada; PHOENICS Hesaplamalı Akışkanlar Dinamiği programının Düşük Reynolds Sayılı Türbülans modeli kullanılmıştır. Bu model çalışmada kullanılan Reynolds sayıları aralığında duvar etkilerini de doğru şekilde modelleyebildiği öngörüldüğünden tercih edilmiştir. Modelleme çalışmasında 96x15x34 (48960 hücre (mash)) kullanılmıştır.

Modelde kullanılan hücre yapısı akış şartlarına göre düzenlenmiştir. Model sonuçlarında daha hassas sonuçlar alabilmek için; jet girişinde, plaka yüzeyinde, hücre yoğunluğu artırılmıştır. Tekrar sayıs1 (sweep number) 400-2500 arasında ve hücre sayısı 20-55 arasında çalışılmıştır. Model sonuçlarının; tekrar sayıs1 600 ve hücre sayıs1 96x15x34 olduğu durumda tekrar sayısında ve hücre sayısından bağımsız olduğu gözlemlenmiştir. 
Sayısal model sonuçları, Li ve arkadaşlarının [22] yapmış olduğu deney sonuçlar ile karşılaştırılmıştır. Deney sonuçları ile karşılaştırma parçacık çap $1 \mathrm{Dp}=25 \mathrm{~nm}$, hacim oranı $\mathrm{Vol}=\% 1,5$ ve $1 \mathrm{~s} 1$ akıs1 q"= $1000 \mathrm{~W} / \mathrm{m}^{2}$ için yapılmıştır. Mevcut çalışmada $\mathrm{Re}=8000$ 'dir. Düşük Re sayılı k- $\varepsilon$ türbülans modelinin kullanıldığ 1 durumda elde edilen sayısal sonuçlar ile deneysel sonuçlar arasındaki farkın $\mathrm{Re}=8000$ için \%10’un altında

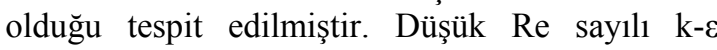
türbülans modeli, standart k- $\varepsilon$ türbülans modeli ve standart k- $\omega$ türbülans modeli ile karşılaştırılmış ve deney sonuçlarını daha iyi bir şekilde temsil edebildiği görülmüştür. $\mathrm{Cu}$-su nanoakışkanı için farklı türbülans modelleri kullanılarak elde edilen sayısal sonuçların deney sonuçlar ile karşılaştırılması Şekil 3'te sunulmuştur.

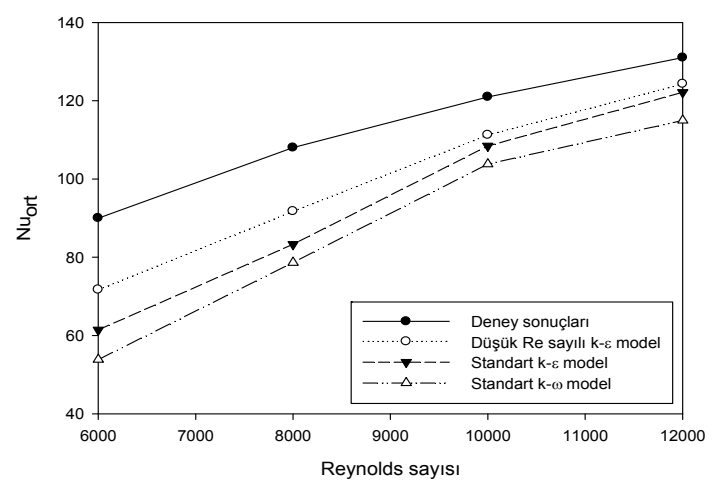

Şekil 3. Model sonuçlarının deney sonuçları ile karşılaştırılması

\section{BULGULAR VE TARTIŞMALAR}

$\mathrm{Bu}$ bölümde; $\mathrm{Cu}-\mathrm{H}_{2} \mathrm{O}$ nanoakışkanının farklı hacim oranlarının $(\% 2, \% 4, \% 6, \% 8)$, farklı 1s1 değerlerinde ( $q=150,200,250,300 \mathrm{~W})$ ve farklı tiplerde hazırlanan nanoakışkanların $\left(\mathrm{Cu}-\mathrm{H}_{2} \mathrm{O}\right.$, $\mathrm{CuO}-\mathrm{H}_{2} \mathrm{O}, \mathrm{TiO}_{2}-\mathrm{H}_{2} \mathrm{O}, \mathrm{Al}_{2} \mathrm{O}_{3}-\mathrm{H}_{2} \mathrm{O}$ ve saf su) $1 \mathrm{~s} 1$ transferine etkisi nanoparçacık çapı $20 \mathrm{~nm}$ için sayısal olarak incelenmiştir.

\subsection{Farklı Hacim Oranlarının (\%2, \%4, \%6, \%8) Isı Transferine Etkisi}

$\mathrm{Bu}$ parametrede $\mathrm{Cu}-\mathrm{H}_{2} \mathrm{O}$ nanoakışkanının farklı hacimsel oranlarda $1 \mathrm{~s} 1$ transferine etkisi, $\mathrm{q}=300 \mathrm{~W}$ için (parametreler içindeki en yüksek 1S1 değerinde) incelenmiştir. Model çalışmanın pratikte uygulanabilirliği değerlendirilerek (uygulamada nanoparçacık miktarının çok fazla artırılması, çökelmeye, parçacıkların homojen olarak dağılmamasına ve basınç kayıplarına sebep olacağından) hacim oranı bu değerler içinde alınmıştır. En iyi 1sı transferinin hacimsel oran $\% 8$ iken sağlandığı görülmüştür. Hacimsel oran $\% 2$ 'den \%8'e artırıldığında ortalama Nusselt sayısında \%15,2 oranında bir iyileşme tespit edilmiştir. Ancak ortalama Nusselt sayısındaki bu artışın, hacimsel oran \%2'den \%4'e çıkarıldı̆̆ında $\% 5,9$ oranında, \%4'ten \%6'ya çıkarıldığında \%4,7 oranında ve \%6'dan \%8'e çıkarıldığında \%3,9 oranında gerçekleştiği gözlemlenmiştir. Böylece, literatürdeki çalışmalara benzer şekilde Teamah ve arkadaşları [2] hacimsel oran arttıkça ortalama Nusselt sayısındaki artışın azalarak devam ettiği tespit edilmiştir. Ayrıca hacimsel oran arttıkça, nanoparçacıkların dönme ve öteleme davranışına bağlı olarak, yüzey üzerindeki duvar jeti bölgesinin daha belirgin şekilde sağlanabildiği, böylece ilave bir jete olan ihtiyacin azaltılabileceği değerlendirilmiştir. Farklı hacim oranlarının yerel Nusselt sayısına etkisi Şekil 4’te sunulmuştur.

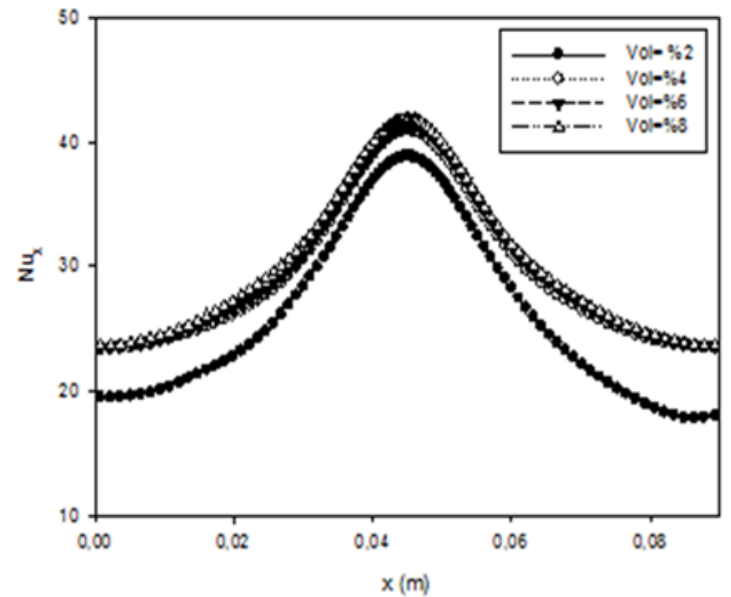

Sekil 4. Farklı hacim oranlarının 1s1 transferine etkisi

Farklı hacim oranları $(\mathrm{Vol}=\% 2$ ve $\mathrm{Vol}=\% 8)$ için hazırlanan hız vektörleri Şekil 5-6'da, sıcaklık konturları Şekil 7-8'de sunulmuştur. 


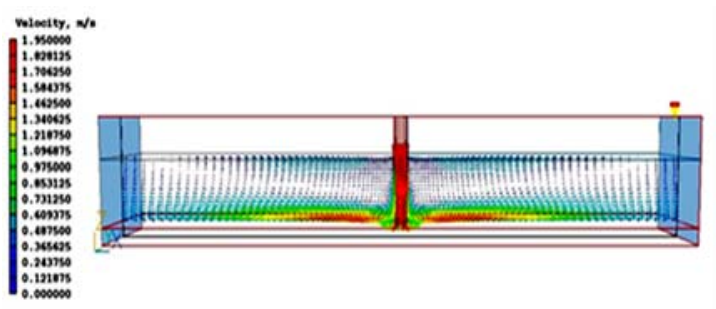

Şekil 5. Vol=\%2 için hız vektörleri

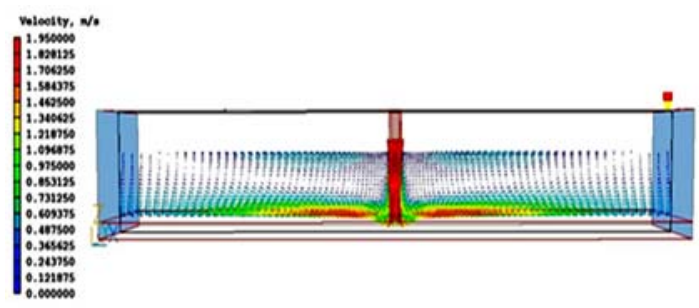

Şekil 6. Vol $=\% 8$ için hız vektörleri

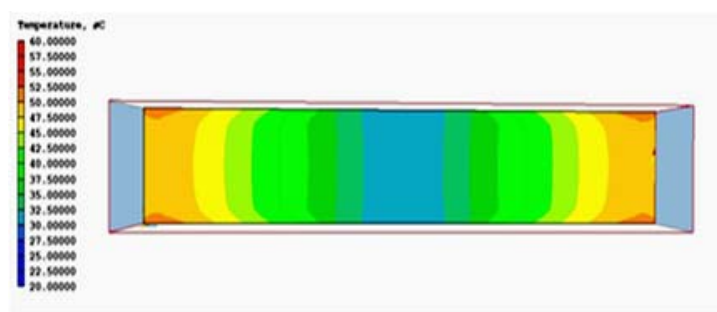

Şekil 7. Vol=\%2 için sıcaklık kontörleri

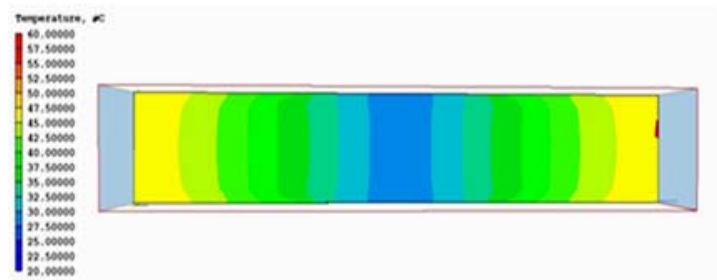

Şekil 8. Vol=\%8 için sıcaklık kontörleri

\subsection{Farklı Isı Değerlerinin $(\mathrm{q}=150,200,250$, $300 \mathrm{~W}$ ) Isı Transferine Etkisi}

Oluşturulan sayısal model $\mathrm{Cu}-\mathrm{H}_{2} \mathrm{O}$ nanoakışkanının farklı 1S1 akılarında (model geometrisi için en uygun hacim oranı olarak belirlenmiş olan $\mathrm{Vol}=\% 4$ değeri için) uygulanmış, yerel sıcaklık değerleri, yerel Nusselt sayısı değerleri, hız vektörleri ve sıcaklık konturları elde edilmiş̧ir. Farklı 1Sı akılarının yerel Nusselt sayısına etkisi Şekil 9'da sunulmuştur.

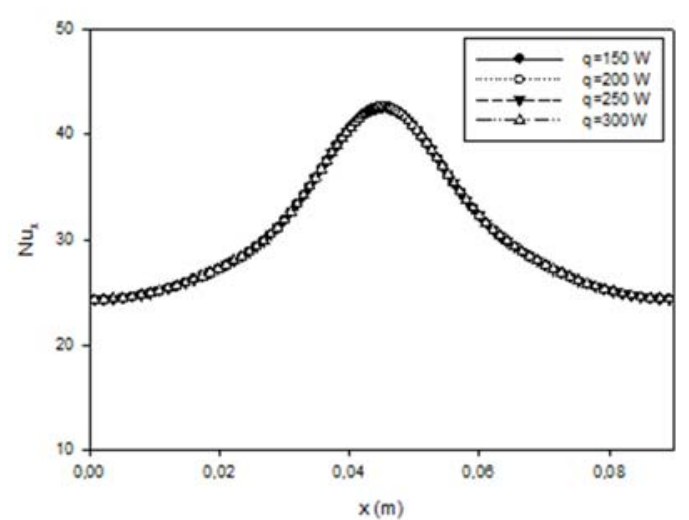

Şekil 9. Farklı 1Sı akılarının 1sı transferine etkisi

Yüzey üzerindeki 1S1 akısı iki kat artırıldığında, yüzey sıcaklıkları artmakta ancak 1S1 akısının artışına bağlı olarak sıcaklık farkının da artması sebebiyle yerel Nu sayısında belirgin bir değişiklik olmadığ 1 (literatürdeki çalışmalara benzer şekilde [17] tespit edilmiştir.

Düşük 1sı akılarında yüzeydeki sıcaklık değişimleri belirgin olmamaktadır. Bundan farklı olarak; 1S1 akısı yükseldikçe yüzeydeki sıcaklık değişimleri (bakırın 1S1 iletim katsayısı oldukça yüksek olmasına rağmen) daha belirgin hale gelmektedir. Duvar kenarlarında hız azalışına ve ısıl sınır tabaka artışına bağlı olarak sıcaklık artışları daha belirgin olarak gözlemlenmiştir. Akışkan hızı aynı olduğu için hız (Reynolds sayısı aynı) tüm 1sı değerlerinde hız vektörleri benzer biçimde oluşmuştur. Farklı 1 sı değerleri $(150 \mathrm{~W}$ ve $300 \mathrm{~W})$ için hazırlanan hız vektörleri Şekil 10-11'de, sicaklık konturları Şekil 12-13’te sunulmuştur.

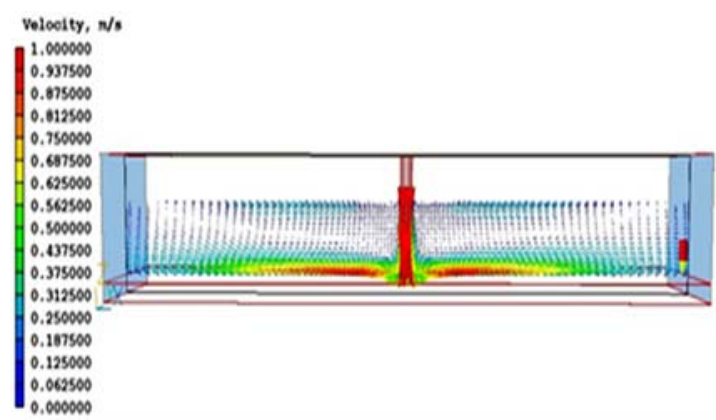

Şekil 10. $150 \mathrm{~W}$ için hız vektörleri 


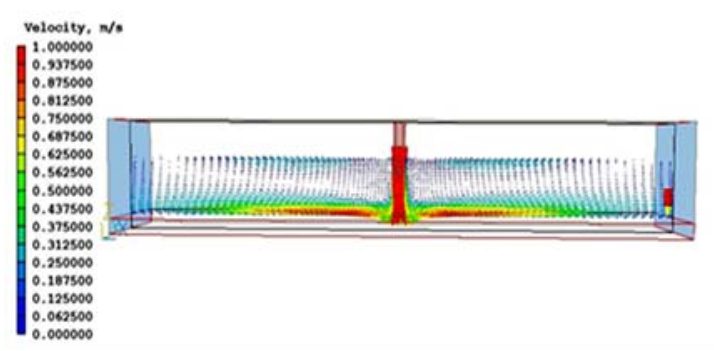

Şekil 11. 300W için hız vektörleri

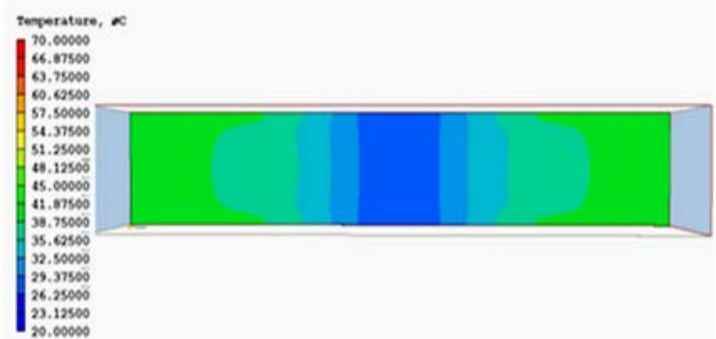

Şekil 12. $150 \mathrm{~W}$ için sıcaklık konturları

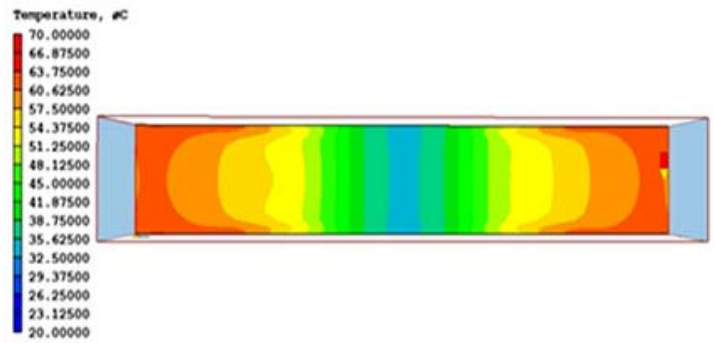

Şekil 13. 300W için sıcaklık konturları

\subsection{Farklı Tiplerde Nanoakıșkanların ( $\mathrm{Cu}$ - $\left.\mathrm{H}_{2} \mathrm{O}, \mathrm{CuO}-\mathrm{H}_{2} \mathrm{O}, \mathrm{TiO}_{2}-\mathrm{H}_{2} \mathrm{O}, \mathrm{Al}_{2} \mathrm{O}_{3}-\mathrm{H}_{2} \mathrm{O}\right)$ isı Transferine Etkisi}

Farklı tipte nanoakışkanların 1S1 transferine etkisinin görmek maksadıyla, nanoakışkanların fiziksel ve termal özellikleri literatürde yer alan korelasyonlar kullanılarak hesaplanmıştır. Nanoakışkaların tespit edilen ve programa akışkan özellikleri olarak girilen özellikleri Çizelge 1'de sunulmuştur. $\mathrm{Cu}-\mathrm{H}_{2} \mathrm{O}$ nanoakışkanın en iyi 1sı transferi performansını gösterdiği tespit edilmiştir. $\mathrm{Bu}$ sonuç; $\mathrm{Cu}-\mathrm{H}_{2} \mathrm{O}$ nanoakışkanının en yüksek 1sı iletim katsayısına sahip olması düşünüldüğünde son derece tutarlı bir sonuçtur. Bunun yanı sıra, $\mathrm{Cu}-\mathrm{H}_{2} \mathrm{O}$ nanoakışkanı kullanılmasi durumunda, ortalama Nusselt sayisinda sirasiyla $\mathrm{CuO}-\mathrm{H}_{2} \mathrm{O}, \quad \mathrm{TiO}_{2}-\mathrm{H}_{2} \mathrm{O}$, $\mathrm{Al}_{2} \mathrm{O}_{3}-\mathrm{H}_{2} \mathrm{O}$ ve saf suya göre $\% 2,6, \% 5,5, \% 6,1$,
\%9,6 iyileşme olduğu gözlemlenmiștir. Farklı nanoakışkanların yerel Nusselt sayısına etkisi Şekil 14'te sunulmuştur.

Çizelge 2. Nanoakışkanların özellikleri

\begin{tabular}{|c|c|c|c|c|c|c|}
\hline Akışkan & $\begin{array}{l}\text { Yoğunluk } \rho \\
(\mathrm{kg} / \mathrm{m} 3)\end{array}$ & $\begin{array}{l}\text { Özgül Ist Cp } \\
\text { (J/kgK) }\end{array}$ & $\begin{array}{l}\text { Dinamik } \\
\text { Viskozite } \\
\mu(\text { Ras.s) }\end{array}$ & $\begin{array}{l}\text { Kinematik } \\
\text { Viskozite }\left(\mathbf{m}^{2} / \mathrm{s}\right)\end{array}$ & $\begin{array}{l}\text { Isll İletim } \\
\text { KKatsaysis } \lambda \\
(\mathbf{W} / \mathrm{mK})\end{array}$ & $\begin{array}{l}\text { Isl Genleșme } \\
\text { Katsayass \& } \\
\left(\mathbf{m}^{2} / \mathrm{s}\right)\end{array}$ \\
\hline $\mathrm{Cu}-\mathrm{H}_{2} \mathrm{O}$ & 1157,436 & 3594,1295 & 0,001044516 & 0,0000 & 0,6422 & 0,0001544 \\
\hline $\mathrm{CuO}-\mathrm{H}_{2} \mathrm{O}$ & 1108,236 & 3754,3113 & 0,001044516 & 0,000000943 & 0,6382 & 0,0001534 \\
\hline $\mathrm{TiO}_{2}-\mathrm{H} 2 \mathrm{O}$ & 1063,237 & 3902,5136 & 0,001044516 & 0,000000982 & 0,6378 & 0,0001537 \\
\hline $\mathrm{Al}_{2} \mathrm{O}_{3}-\mathrm{H}_{2} \mathrm{O}$ & 1055,838 & 3931,4512 & 0,001044516 & 0,000000989 & 0,6391 & 0,0001540 \\
\hline & 998,2 & 4182,0 & 0,000993 & 0,000000990 & 0,597 & 0,0001430 \\
\hline
\end{tabular}

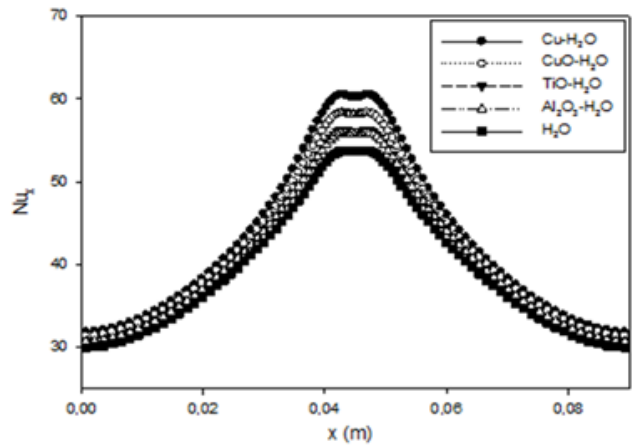

Şekil 14. Farklı nanoakışkanların yerel Nusselt sayısına etkisi

$\mathrm{Cu}-\mathrm{H}_{2} \mathrm{O}$ nanoakışkanın kullanıldığı durumda saf suya göre duvar jeti bölgesinde hız konturlarının daha belirgin şekilde oluştuğu tespit edilmiştir. Bunun sebebinin; nano parçacıkların çarpma ve öteleme davranışının sebep olduğu yüzeye yakın bölgede oluşan girdaplara bağlı olarak, hidrodinamik sınır tabaka kalınlığının artması olduğu değerlendirilmektedir. Buna bağlı olarak; yalnızca çarpma bölgesinde değil, duvar jeti bölgesinde de hidrodinamik sınır tabaka belirgin bir şekilde oluşabilmiş ve isıl sınır tabaka azalmasına bağlı olarak yüzey sıcaklıklarında düşme gözlemlenmiştir. $\mathrm{Cu}-\mathrm{H}_{2} \mathrm{O}$ ve saf su için elde edilen hı vektörleri Şekil 15 ve 16 'da sunulmuştur.

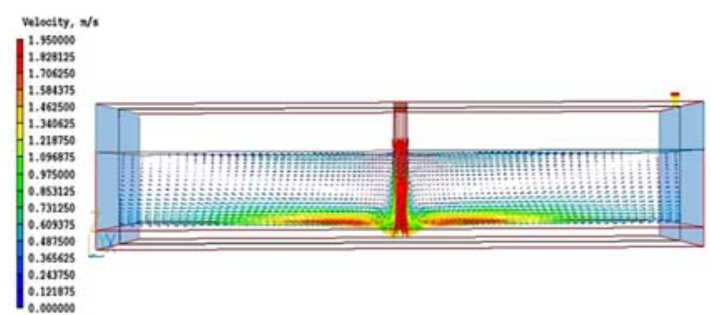

Şekil 15. $\mathrm{Cu}-\mathrm{H}_{2} \mathrm{O}$ nanoakışkanı için hız vektörleri 


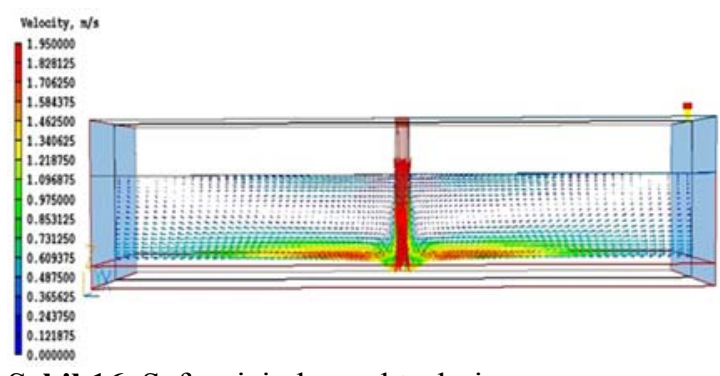

Şekil 16. Saf su için hız vektörleri

$\mathrm{Cu}-\mathrm{H}_{2} \mathrm{O}$ nanoakışkanın kullanıldı $\breve{1} 1$ durumda saf suya göre yüzeydeki sıcaklık değerlerinin özellikle çarpma bölgesinde belirgin şekilde azaldığı, buna bağlı olarak oluşan momentum transferi sebebiyle hızlanan akışkanın ısıl sınır tabaka kalınlığını azalttığı tespit edilmiştir. Nanoakışkan kullanılma durumunda duvar jeti bölgesinde de belirgin şekilde sıcaklık düşüşleri tespit edilmiştir. Özellikle duvara yakın bölgelerde akışkan hızının azalmasına bağlı olarak oluşan yüksek sıcaklık bölgeleri nanoakışkan kullanılma durumunda oldukça azalmıştır. Bu durumun nano parçacıkların bu bölgelerde oluşturdukları nano boyuttaki girdaplardan kaynaklandığı tespit edilmiştir. $\mathrm{Cu}-\mathrm{H}_{2} \mathrm{O}$ nanoakışkanı ve saf su için elde edilen sıcaklık konturları Şekil 17 ve 18 'de sunulmuştur.

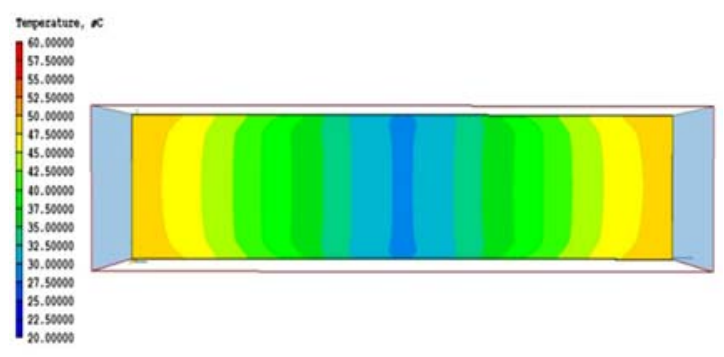

Şekil 17. $\mathrm{Cu}-\mathrm{H}_{2} \mathrm{O}$ nanoakışkanı için sıcaklık konturlar1

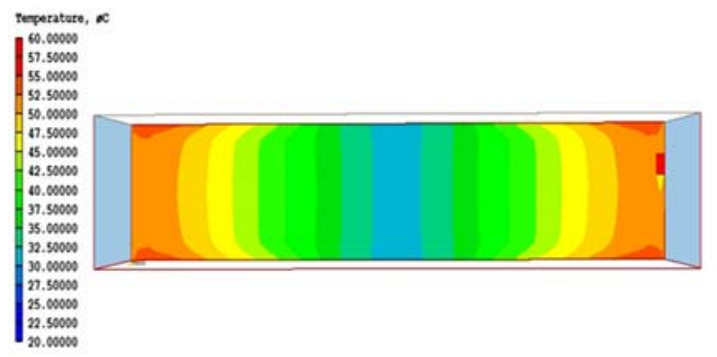

Şekil 18. Saf su için sıcaklık konturları

\section{SONUÇ}

Bu çalışmanın amacı; yüksek 1sı akılı elektronik devre elemanlarının, farklı tipte nanoakışkanlar ve çarpan akışkan jet kullanılarak soğutulmasında, 1sı transferinin ve akış özelliklerinin incelenmesidir. $\mathrm{Bu}$ maksatla; elektronik devre elemanlarını modelleyen bakır bir plakadan olan isı transferinin iyileştirilmesinde çarpan akışkan jetlerin ve farklı tipteki nanoakışkanların etkisi belirlenmeye çalışılmıştır. Sonuç olarak;

En iyi 1s1 transferinin hacimsel oran \%8 iken sağlandığı görülmüştür. Hacimsel oran $\% 2$ 'den $\% 8$ 'e artırıldığında ortalama Nusselt sayısında $\% 15,2$ oranında bir iyileşme tespit edilmiştir. Hacimsel oran \%2'den \%4'e arttıkça ortalama Nusselt sayıs1 \%5,9 oranında, \%4'ten \%6'ya arttığında $\% 4,7$ oranında ve $\% 6$ 'dan $\% 8$ 'e arttı̆̆ında \%3,9 artış olduğu gözlemlenmiştir.

Yüzeydeki 1S1 akısı iki kat artırıldığında, yüzey sıcaklıkları artmakta ancak 1sı akısının artışına bağlı olarak sıcaklık farkının da artması sebebiyle yerel Nusselt sayısında belirgin bir değişiklik olmadığ 1 tespit edilmiştir.

$\mathrm{Cu}-\mathrm{H}_{2} \mathrm{O}$ nanoakışkanı kullanılması durumunda, ortalama Nusselt sayisinda sirasiyla $\mathrm{CuO}-\mathrm{H}_{2} \mathrm{O}$, $\mathrm{TiO}_{2}-\mathrm{H}_{2} \mathrm{O}, \mathrm{Al}_{2} \mathrm{O}_{3}-\mathrm{H}_{2} \mathrm{O}$ ve saf suya göre $\% 2,6$, $\% 5,5, \quad \% 6,1, \quad \% 9,6 \quad$ iyileşme olduğu gözlemlenmiş̧ir.

Numerik çalışmada kullanılan, PHOENICS Hesaplamalı Akışkanlar Dinamiği programının Düşük Reynolds Sayılı Türbülans modelinin duvar etkilerini de dikkate aldığından deney sonuçları ile oldukça uyumlu sonuçlar verdiği $(\mathrm{Re}=8000$ için $\% 10$ 'un altındadır) tespit edilmiştir.

$\mathrm{Bu}$ alanda yapılacak gelecek çalışmalarda devre elemanlarının daha verimli bir şekilde soğutulabilmesi maksadıyla; çarpan jetlerde hibrid nanoakışkanların (ferromanyetik vb.) kullanılmasının yüzeyde oluşan ısı transferine ve akış karakteristiğine etkisinin, farklı sistem geometrileri için incelenmesinin faydalı olacağ değerlendirilmiş̧tir. 


\section{TEŞEKKÜR}

$\mathrm{Bu}$ çalışma, Adana Bilim ve Teknoloji Üniversitesi'nin Bilimsel Araştırma Projeleri birimi tarafından desteklenmiştir (Proje No: 16103021 ve 18103006$)$.

\section{KAYNAKLAR}

1. Abdulvahitoğlu, A., Aydın K., 2012. Performance and Exhaust Emission Characteristics of a CI Engine Fueled with Synthesized Fuel Blends, Energy Education Science and Technology Part A: Energy Science and Research, 2, 699-710.

2. Teamah, M.A., Dawood, M.M., Shehata, A., 2015. Numerical and Experimental Investigation of Flow Structure and Behavior of Nanofluids Flow Impingement on Horizontal Flat Plate, Experimental Thermal and Fluid Science, 74, 235-246.

3. Manca, O., Ricci, D., Nardini, S., Lorenzo, G., 2016. Thermal and Fluid Dynamics Behaviours of Confined Laminar Impinging Slot Jets with Nanofluids, International Communications in Heat and Mass Transfer, 70, 15-26.

4. Qu, J., Wu, H.Y. Cheng, P., 2010. Thermal Performance of an Oscillating Heat Pipe with $\mathrm{Al}_{2} \mathrm{O}_{3}$-Water Nanofluids, International Communication Heat and Mass Transfer, 37, 111-115.

5. Lv, J., Chang, S., Hu, C., Bai, M., Wang, P., Zeng, Ke., 2017. Experimental Investigation of Free Single Jet Impingement using $\mathrm{Al}_{2} \mathrm{O}_{3}$-water Nanofluid, International Communication in Heat and Mass Transfer, 88, 126-135.

6. Khaleduzzaman, S.S., Sohel, M.R., Saidur, R., Mahbubul, I.M., Akash, B.A., Selvaraj, J., 2014. Energy and Exergy Analysis of Alümina-water Nanofluid for an Electronic Liquid Cooling System, International Communication in Heat and Mass Transfer, 57, 118-127.

7. Shang, F.M., Liu, D.Y., Xian, H.Z., Yang, Y.P. Du, X.Z. 2007. Flow and Heat Transfer Characteristics of Different Forms of Nanaometer Particles in Oscillating Heat Pipe, Journal of Chemical Industry, 58, 2200-2204.
8. Wang, P., Lv, P., Bai, M., Wang, Y., Hu, C., 2014. A Numerical Investigation of Impinging Jet Cooling with Nanofluids, Nanoscale and Micrescale Thermophysical Engineering, 18, 329-353.

9. Sun, B., Qu, Y., Yang, D., 2016. Heat Transfer of Single Impinging Jet with $\mathrm{Cu}$ Nanofluids, Applied Thermal Engineering, 102, 701-707.

10. Umer, A., Naveed, S., Ramzan, N., 2015. Experimental Study of Laminar Forced Convection Heat Transfer of Deionized Water Based Copper (I) Oxide Nanaofluids in Tube with Constant Wall Heat Flux, Heat Mass Transfer, 52, 2015-2025.

11. Kang, S.W., Wei, W.C., Tsia, S.H., Yang S.H., 2006. Experimental Investigation of Silver Nanofluid on Heat Pipe Thermal Performance, Applied Thermal Engineering, 26, 2377-2382.

12. Lv, J., Hu, C., Bai, M., Zeng, K., Chang, S., Gao, D., 2017. Experimental Investigation of Free Single Impingement using $\mathrm{SiO}_{2}$-water nanofluid, Experimental Thermal and Fluid Science, 84, 39-46.

13. Singh, M., Yadav, D., Arpit S., Mitra S., Saha, S.K., 2016. Effect of Nanofluid Concentration and Composition on Laminer Jet Impinged Cooling of Heated Steel Plate, Applied Thermal Engineering, 100, 237-246.

14. Kilic, M., Ozcan, O., 2017. Numerical Investigation of Heat Transfer and Fluid Flow of Nanofluids with Impinging jets, International Conference On Advances and Innovations in Engineering (ICAIE), 434-440.

15. Nayak, S.K., Mishra, P.C., Parashar, S.K., 2016. Enhancement of Heat Transfer by Water $-\mathrm{Al}_{2} \mathrm{O}_{3}$ and Water-TiO ${ }_{2}$ Nanofluids Jet Impingement in Cooling Hot Surface Steel Surface, Journal of Experimental Nanoscience, 11, 1253-1273.

16. Yan, W.M., Liu, H.C., Soong, C.Y., Yang, W.J., 2005. Experimental Study of Impinging Heat Transfer Along Rib-roughened Walls by using Transient Liquid Crystal Technique, Heat and Mass Transfer, 48, 2420-2428.

17. Kilic, M., Çalışır, T., Başkaya, Ş., 2017. Experimental and Numerical Study of Heat Transfer from a Heated Flat Plate in a Rectangular Channel with an Impinging Jet, 
Journal of the Brazilian Society of Mechanical Sciences and Engineering, 39(1), 329-344.

18. McGuinn, A., Persoons, T., O'donovan, T., Murray, D., 2007. Surface Heat Transfer from an Impinging Synthetic Air Jet, International Journal of Heat and Mass Transfer, 20, 1333-1338.

19. Isman, M.K., Pulat, E., Etemoglu, A.B., Can, M., 2008. Numerical Investigation of Turbulent Impinging Jet Cooling of a Constant Heat Flux Surface, Numerical Heat Transfer, 53(10), 1109-1132.

20. Kilic, M., Baskaya Ş., 2017. Improvement of Heat Transfer from High Heat Flux Surfaces by using Vortex Promoters with Different Geometries and Impinging Jets, Journal of the Faculty of Engineering and Architecture of Gazi University, 32(3), 693-707.

21. Corcione, M., 2011. Empirical Correlating Equations for Predicting the Effective Thermal Conductivity and Dynamic Viscosity of Nanofluids, Energy Conversion and Management, 52(1), 789-793.

22. Li, Q., Xuan, Y., Yu, F., 2012. Experimental Investigation of Submerged Single Jet Impingement using $\mathrm{Cu}$-water Nanofluid, Applied Thermal Engineering, 36(1), 426-433. 